\title{
Reincidencia, reintegración social y medios de comunicación
}

\section{Recidivism, Social Reintegration and Mass Media}

Omar O. López Sinisterra*

http://dx.doi.org/10.21503/lex.v15i19.1385

* Abogado y magíster en Criminología y Seguridad Humana, Universidad de Panamá.

E-mail: tokuterada@yahoo.es

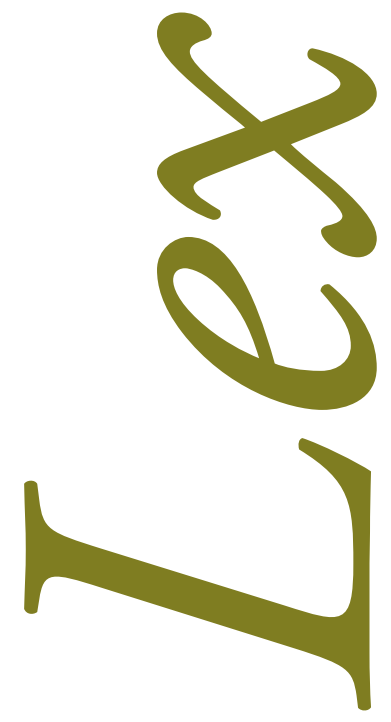

(c) (1) (C) Los autores. Artículo publicado por la Revista Lex de la Facultad de Derecho y Ciencias Políticas de la Universidad Alas Peruanas. Este es un artículo de acceso abierto, distribuido bajo los términos de la Licencia Creative Commons Atribución-No Comercial-Compartir Igual 4.0 Internacional.(http://creativecommons.org/licenses/by-nc-sa/4.0/), que permite el uso no comercial, distribucion y reproduccion en cualquier medio, siempre que la obra original sea debidamente citada. 


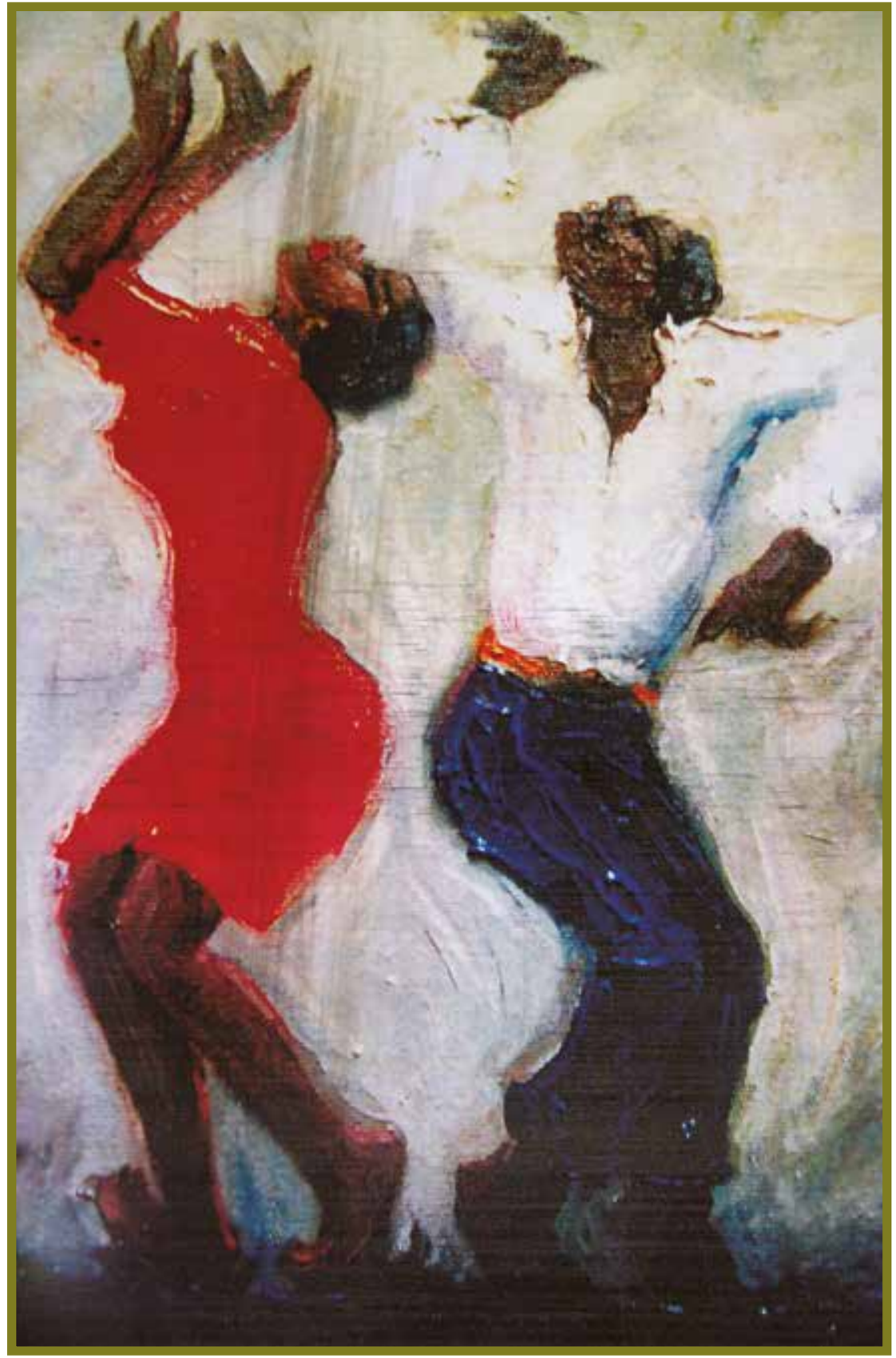

Festejo. Óscar Allaín 


\section{RESUMEN}

La reincidencia delictiva consiste en la reiteración del delito en un tiempo determinado, del mismo tipo al anterior o diferente. Los Gobiernos han estructurado programas de reintegración social que han pretendido disminuir la reincidencia y lograr que los convictos se constituyan en seres socialmente productivos. Sin embargo, se necesitan ingentes recursos para llegar a tal meta con el éxito deseado, situación que no ocurre en nuestros países. La criminalidad se exacerba y más cuando los medios de comunicación la potencializan en frecuencia, duración e intensidad, comunicando este tipo de noticias en forma impactante, y de la mano con esta situación, se incrementa en ocasiones la dureza de las penas modificando las normas penales y dejando de lado los programas que pretenden reintegrar a los internos a la vida social.

Palabras clave: reincidencia, criminalidad, reintegración social, medios de comunicación.

\section{ABSTRACT}

Criminal recidivism consists in the repetition of the crime - the same or different - in a given time. Governments have structured social reintegration programs intended to reduce recidivism and turn convicts into socially productive persons. However, enormous resources are needed to reach this goal with the desired success, which does not happen in our countries. Criminality is more than exacerbated when the mass media strengthen its frequency, duration and intensity by communicating crime related news in an impacting manner, and hand in hand with this situation, the harshness of penalties are increased changing criminal laws and leaving aside the programs intended to reintegrate inmates into social life.

Key words: recidivism, criminality, social reintegration, mass media. 
La reincidencia delictiva es un fenómeno de vieja data en la historia de la criminalidad. El término proviene del latín reincidere, que significa volver a hacer.

Desde la antigüedad, la reincidencia se ha considerado como un agravante de la pena en procesados que poseen estos antecedentes; sin embargo, en muchas legislaciones no se considera como tal.

El aumento o disminución de la criminalidad ha dependido de las políticas en materia de seguridad y criminológicas en los países, aunado esto al tipo, calidad y cantidad de la publicidad que ejercen los medios de comunicación. La exacerbación de políticas de "mano dura" de las administraciones gubernamentales y de los medios de comunicación tienen efectos nocivos en el desarrollo de la criminalidad.

Bañón Aguilera, ${ }^{1}$ en referencia a la acción de los medios de comunicación, señala que "preguntarse sobre el tratamiento mediático de la delincuencia, entendida en este caso particular como el fenómeno de la comisión de delitos, conlleva a responder dos cuestiones: 1) la primera es cuánto espacio dedican los medios de comunicación a la delincuencia, 2) la segunda es la forma en que se habla de la delincuencia, cómo se informa de ella".

Es importante la forma en que se habla de la delincuencia si las noticias son muy sensacionalistas y repetitivas aludiendo a la existencia de una crisis de seguridad pública, pues existirá una gran preocupación social sobre el tema de la criminalidad, y más aún si se trata de delitos atroces o violentos ejercidos contra la integridad humana, lo que ejerce definitiva acción sobre la necesidad de endurecer las penas y tomar medidas rígidas en materia de seguridad.

Este fenómeno nuevamente incide en los procesos llevados a efecto sobre los reincidentes delictivos. Se incorpora a la ley penal la reincidencia como un elemento agravante de la pena.

Juan María Bañón, “Medios de comunicación, opinión pública y política criminal”, 27 de octubre de 2015, acceso el 17 de febrero de 2017, http://decrimweebly.com 
Los momentos en los cuales esta información es muy utilizada, es durante las campañas políticas electorales para lograr regir los destinos de los países, en donde los candidatos en el tema de seguridad pública plantean medidas extremas para mantener el ordenamiento y la seguridad social que ha sido alterada por los acontecimientos criminales evocados en los medios de comunicación, creando preocupación y malestar en la población en base a noticias criminosas con imágenes continuas y distorsionadas del acontecer criminal. Toledo Campos, ${ }^{2}$ frente a la actitud de la población en función de la información de los medios de comunicación, puntualiza que "pese a que las cifras de delitos están estancadas estadísticamente, la percepción ciudadana parece estar muy sobre lo que indican los datos. Esto no solo revela una distorsión de la realidad, sino también da cuenta de una administración mediática del miedo, que construye estereotipos y temores infundados".

También es cierto que, dependiendo de la postura de los medios en materia de la acción criminal, se enmascaren otros tipos de delito como los económicos o los de "cuello blanco", por la magnificación del tema sobre criminalidad y más aún si se trata de noticias como asesinatos cruentos y atroces, de forma repetitiva que una vez llevados a la impresión noticiosa, se dejan de lado en importancia los delitos por lavado de dinero, soborno y coimas, compra de funcionarios públicos en los órganos ejecutivo, legislativo y judicial, y que hoy en día se encuentran en la palestra pública en nuestros países (tales como Lava Jato, Odebrecht y Panamá Papers).

Es de primera importancia que la percepción social esté basada en noticias reales de los hechos acaecidos y que no sufran ningún tipo de distorsión.

Soto Navarro $3^{3}$ señala que "el poder de los medios de comunicación en las sociedades modernas está sobradamente estudiado, sobre todo en ámbitos de inminente interés práctico como son la publicidad de bienes de consumo y servicio de las campañas electorales".

Si los programas y medios utilizados en los centros penitenciarios no cumplen con los programas de reintegración, o de reinsertar debidamente a los convictos durante su estadía en las cárceles y su posterior egreso de las mismas, es probable que, al regreso al nicho de origen, el sujeto sea nuevamente absorbido por su medio social y vuelva a delinquir. Y si delinque realizando crímenes de alto perfil en un ámbito en el que se potencializan las noticias sobre el tema y ocurre en el momento preciso de los avatares políticos, surgen posturas políticas presentando esquemas de soluciones para el saneamiento y erradicación de la criminalidad. Por supuesto que retomar acciones para reincorporar a estos delincuentes a la sociedad de manera productiva en un momento como el que antecede se hace mucho más difícil.

2 Manuel Toledo Campos, "Medios de comunicación y delincuencia: amplificación del miedo y creación de estereotipos", Dircom, Revista de la Universidad de Chile (2017): 1, www.uchile.cl

3 Susana Soto Navarro, "La influencia de los medios en la percepción social de la delincuencia", Revista Electrónica de Ciencia Penal y Criminología (2005), Criminet.ugr.es. 
El campo fértil que preparan los medios de comunicación en función de sus intereses de acuerdo a la problemática generada por la criminalidad, con una noticia magnificada o potencializada, crea inseguridad e incertidumbre en la población. El temor, la inseguridad y el desacierto que vive la población cataliza cualquier postura política, legislativa o judicial que tienda a aumentar las penas y las medidas que se tomen con aquellos que violen la ley y sobre todo en su reiteración.

Aquellos que pugnan por implantar programas de reintegración social en las cárceles ven una ventana luminosa que permite una oportunidad a aquellos que han cometido delitos, para poder regenerarlos y convertirlos en seres socialmente productivos.

Los programas de reintegración, también conocidos como de resocialización o reinserción, contienen valiosos y diversos aprendizajes de tipo vocacional, actitudinales, espirituales y paralelamente, educativos.

Estos programas, en el mejor de los casos, pueden lograr cambios en estos individuos si son llevados a efecto correctamente y si poseen todos los insumos necesarios, que pueden ser otorgados por un presupuesto adecuado en función de un buen apoyo gubernamental.

En Panamá, desde el 2014, se han realizado iniciativas entre el Ministerio de Gobierno y la Universidad de Panamá. Se han desarrollado programas en el Centro Femenino de Rehabilitación, y entre ellos el Técnico en Confección y Vestuario (modas), el Técnico en Comunicación Bilingüe con énfasis en centros de llamadas, licenciatura en Turismo histórico Cultural y la licenciatura en Desarrollo Comunitario. Estos programas se han desarrollado en el Centro Regional de San Miguelito, el cual es un distrito populoso del país. Las aulas de esta excelente iniciativa han sido financiadas por la Oficina de las Naciones Unidas Contra la Droga y el Delito (UNDOC).

Setenta estudiantes internas en este centro femenino de rehabilitación han participado en este programa que sienta precedentes en la historia, indicando que sí es posible reintegrar a las internas e internos a través de estos programas. Algunas de ellas ya han egresado del programa, se encuentran en libertad y cursando estudios universitarios en la Universidad de Panamá. ${ }^{4}$

La Universidad de Panamá, de acuerdo a sus funciones de extensión, está realizando estos programas en la geografía del país. En el centro femenino de rehabilitación en la provincia de Coclé, se están desarrollando los mismos. En esta tarea, existen alianzas con el Ministerio de Educación (MEDUCA), el Ministerio de Gobierno y Justicia y otros.

4 Dirección General del Sistema Penitenciario, "DGSP y UP buscan introducir carreras universitarias en centros penitenciarios a nivel nacional”, acceso el 26 de febrero de 2017, www.sistemapenitenciario.gob.pa 
Los medios de comunicación en dependencia de los intereses existentes, consolidan, le dan prevalencia y sobredimensionamiento a la noticia que desean llegue hasta la población. Cuando esto ocurre, se genera una gran preocupación y malestar social que desemboca en un gran clamor por la seguridad en el país. Al respecto, Fuentes Osorio" señala que "así mismo, es capaz de provocar y dirigir un debate público en el que se enfrenten los distintos planteamientos sobre las causas y las medidas de acción que han sido presentados como existentes por los medios".

El autor señala que cuando se da la comunicación de los hechos criminales, dada la tergiversación de la misma, pueden existir errores de cognición, y se exalta el miedo personal y la posibilidad de constituirse en una posible víctima y la búsqueda de una mayor seguridad para su tranquilidad y solicitando desde luego la intervención penal del Estado.

Ante alarmantes noticias sobre la calidad y la cantidad de los hechos criminales, la sociedad convulsiona y reacciona con temor solicitando se tomen medidas duras sobre la delincuencia, y a la vez señalando la incapacidad de la justicia ante los graves acontecimientos.

Los medios de comunicación se alejan de la imagen real de los acontecimientos, presentando una imagen distorsionada de la realidad. Se crea un clima innecesario en la comunidad por la forma en que se vierte la información. Según este autor, la información no es inocente, y como ya lo hemos afirmado con antelación, los medios funcionan de acuerdo a sus propios intereses y de la clase gobernante, pues en muchos casos, son los dueños de estas empresas de comunicación.

Esta situación posee relevante importancia en el impacto que genera la noticia en la población. Noticias alarmantes, inquietantes o preocupantes, producen una crisis que lleva a las mayorías en este caso por la criminalidad existente, solicitar se tomen medidas con los delincuentes.

Cuando los medios dan realce a delitos tales como secuestros, ejecuciones, muertes por pandillerismo, robos a entidades bancarias y comerciales (restaurantes), secuestro y violación, crímenes atroces, de forma reiterada (frecuencia, duración, intensidad), se crea un ambiente de inseguridad que genera la crisis social. Las personas no acuden a centros comerciales después de las 6:00 p. m., ni a bares o discotecas en la noche por temor a ser presa de la criminalidad existente. La seguridad se ve reforzada en los hogares de aquellos que pueden pagar por ella. Se adquieren equipos de vigilancia (videocámaras), cercas electrificadas, distintos tipos de alambrado cortante, agencias de seguridad y unidades policiales. Algunos adquieren armas con o sin permiso para portarlas para su autodefensa en hogares y comercios.

5 Juan Luis Fuentes Osorio, "Los medios de comunicación y el derecho penal", Revista Electrónica de Ciencia Penaly Criminología (2005): 3, https://dialnet.unirioja.es 
En materia de innovaciones en la actividad criminal, existen nuevas modalidades en Panamá con asaltos a residencias, incluidos el robo de autos y la violación carnal. Hace algunos años, en nuestro país los residentes lavaban sus autos en el hogar con mucha tranquilidad. Hoy en día se llevan los autos a centros de lavado, pues no existe seguridad en los hogares. Es posible que en un futuro los centros de lavado también sean objeto y blanco de la actividad criminal, al igual que las estaciones expendedoras de combustible.

Según Maciel, ${ }^{6}$ "en Uruguay seis de cada diez uruguayos sienten que el país es cada vez más inseguro".

En el mismo reporte, se indica que Uruguay es el segundo país en toda Latinoamérica en identificar la seguridad pública como su principal problema. Pero no solo se presenta en Uruguay, sino en toda América Latina. Es una situación en la cual los Gobiernos aseguran la disminución de la criminalidad, mientras la percepción del pueblo es totalmente contraria.

El autor referido también hace alusión a datos del Ministerio del Interior en los cuales un $50 \%$ de los presos liberados reincide (narcos y ladrones de poca monta).

Algunos países han tomado ciertas medidas contra la reincidencia delictiva conocida como la "Ley del tercer delito o regla penal de reincidencia múltiple", para castigar a aquellos que reiteran el delito. Otros han eliminado beneficios que se les ha otorgado a los internos en los penales.

Frente a esta situación, algunos legisladores han propuesto cambios en las codificaciones y normas penales, duplicando las penas y eliminando algunos de los beneficios que han sido otorgados. Estas constituyen reacciones propias de los Gobiernos a través de las cámaras o asambleas legislativas, proponen reformas en función de la grave situación de los países en función de la criminalidad.

En referencia a las noticias, los periodistas cumplen su función de acuerdo a la ética profesional, pero apegados a las líneas editoriales de los medios en que laboran. Es una situación de injerencia política, pública y de mercado, frente a un problema real que vive la sociedad en nuestros países. Sin embargo, en nuestro criterio, no existe una verdadera política, planes y programas en materia de reinserción, reintegración o resocialización social. Y es sencillo porque se necesita primeramente una férrea voluntad política o muchas ganas de atacar el problema de la reincidencia, una gran inversión a través de un buen presupuesto, y excelentes programas para producir cambios en los internos y reincidentes, para que no vuelvan a delinquir y se conviertan en entes sociales productivos.

6 Guillermo Maciel, “Un problema acuciante: la reincidencia delictiva”, acceso el 30 de septiembre 2005, eltelescopio.com.uy. 
Es mucho más fácil crear nuevas leyes de endurecimiento de las penas y más aún con una batería de información que genere preocupación en la población. En referencia a los medios, deben estar accionando en función de los mejores intereses de la sociedad, en un ámbito que obedezca a realidades objetivas de los sucesos que acontecen en cada país y dándole prelación en importancia para el beneficio social.

Se hace referencia a la reintegración social en la Guía de Introducción a la prevención de la reincidencia y la reintegración social de los delincuentes, ${ }^{7}$ donde se señala que:

La integración social se refiere a un proceso de integrarse social y psicológicamente en el entorno social. Sin embargo, en los campos de prevención del delito y justicia penal, en donde se la usa con frecuencia, el término se refiere más específicamente a las diversas formas de intervención y programas individuales para evitar que se vean involucrados en conductas delictivas o vuelvan a delinquir.

Finalmente, la labor de los medios de comunicación es mantener informada a la población sobre los acontecimientos delictivos, sin magnificar el tiempo, ni tergiversar la información, ni mantenerla por excesivo tiempo en el espacio informativo.

Los Gobiernos deben emanar políticas públicas, planes, programas y presupuestos adecuados para realizar efectivos programas de reintegración, y a la vez crear leyes adecuadas para ofrecer el correcto tratamiento a la criminalidad en el marco de la justicia y la equidad.

Nos preguntamos la razón y la naturaleza de la reincidencia. Para el individuo común, el ciudadano de nuestra comunidad diría: porque le gusta delinquir. Sin embargo, hay que hilar fino y profundamente para observar cuáles factores inciden en que ocurra el fenómeno. Tenemos que ver que el individuo que reincide en la comisión de un delito ya ha cursado pena por los centros penitenciarios. ¿Cómo son los centros penitenciarios?, ¿son acaso estructuras especiales destinadas a castigar al individuo, o a tratar de rehabilitarlo y reintegrarlo productivamente a la sociedad? No necesitamos escudriñar estas estructuras y ver en profundidad sobre las conciencias de los internos para tener una clara idea de lo que ocurre. Nuestros países a través de sus Gobiernos no consideran como prioridad elevar presupuestos para atender a los centros penitenciarios. Muchos de estos centros se caracterizan por ser contenedores de internos sin diferenciarlos por edades, condición sistémica, tipo de crimen cometido, incapacidades, educación, zonas de proveniencia y otros, de modo que puedan ser guiados y orientados para su futura conversión en individuos productivos.

7 ONUDD (Oficina de las Naciones Unidas Contra la Droga y el Delito), Guía de Introducción a la prevención de la reincidencia y la reintegración social de los delincuentes (Nueva York: ONUDD, 2013), 1, acceso el 24 de febrero de 2017, https://www.unodc.org 
Estas estructuras son cajones de hacinamiento en donde impera la ley del más fuerte. Donde el ocio impera para que exista la posibilidad de perpetrar actos criminales dentro del recinto. Donde existen condiciones insalubres y los baños se destinan a muchos individuos para su uso y están en pésimas condiciones. En donde los equipos destinados para los programas de reintegración (aprendizajes vocacionales) están dañados y en el mejor de los casos no existe el personal idóneo para atenderlos. En donde existe un mercado negro de la droga y trasiego de armas blanca y de fuego. En donde existe un grado de corrupción que consume las entrañas del personal custodio y policial, pero que muchas instituciones hacen sinergia para mejorar la situación en ellos.

Hay que tener voluntad política para accionar sobre los centros penitenciarios y creer que sí es posible reintegrar a los individuos que han cometido delitos. Hay que creer en los programas de reintegración social y apoyarlos de manera franca.

Desde hace unos años, el nuevo modelo de los centros penales existente en República Dominicana permite que los internos tengan facilidades para su vivencia en el recinto. Allí, según Pimentel, ${ }^{8}$ "cada recluso tiene su cama, contrario a lo que ocurre en los recintos del viejo modelo penitenciario, en donde cada quien debe arreglárselas como pueda para poder dormir, incluso sobre un cartón que no tiene más base que el duro, frío y sucio suelo".

Tal y como se hace referencia en este artículo, muchos de los centros penales de nuestra América Latina poseen graves condiciones en su infraestructura y albergan a miles de reclusos en total hacinamiento.

Es necesario también que una vez que los internos egresen del centro penitenciario y después de haber culminado exitosamente su programa de reinserción con capacidades para ser absorbido por la empleomanía en un área de la comunidad, deben ser monitoreados o darles efectivo seguimiento de sus actividades productivas y sociales. Primeramente, estos internos deben ser reubicados en zonas que las denomino "zonas agradables", para que sea posible su efectiva reinserción. $Y$ es que si no se toman las providencias necesarias para su debida reinserción y su seguimiento, los egresados del sistema retornan a sus nichos originales en donde nuevamente pueden ser absorbidos por pandillas, los narcotraficantes, o sencillamente vuelven a perpetrar otro delito.

El Estado a través de sus Gobiernos de turno debe crear una dependencia en el Ministerio de Seguridad, en la Dirección de los Centros Penitenciarios, que se encargue de monitorear y darles seguimiento a los egresados de los penales y que hayan efectivamente recibido los programas de reintegración social. Esto además de su reubicación en un nicho agradable en donde puedan reiniciar su vida en productividad.

8 Kharla Pimentel, “Del viejo al nuevo modelo penitenciario”, acceso el 28 de febrero de 2017, Acento.com.do. 
En los Centros de Cumplimiento para menores de edad, los internos también son incluidos en programas de reintegración, y se debe tener la previsión de que una vez cumplan los 18 años de edad, no sean enviados a centros considerados como "escuelas para el crimen".

\section{CONCLUSIONES}

Los medios de comunicación son de gran importancia para mantener a la población informada de todos los temas que ocurren en cada país. En la emisión de la noticia no deben prevalecer intereses personales, políticos o gubernamentales que puedan tergiversarla y crear una crisis en la población en materia de seguridad, como lo es efectivamente en los eventos noticiosos de la actividad criminal. Creemos que los medios también deben obedecer a la ética profesional, que debe constituirse en el norte de todas sus acciones. Los buenos programas y las buenas obras que se realizan para disminuir la reincidencia y la criminalidad en los países deben ser evidenciados a través de los medios de comunicación.

Los Gobiernos de nuestros países deben considerar la importancia de los diferentes programas de reinserción y la posibilidad de realizar programas educativos informales y formales en los centros penitenciario con el apoyo de las entidades públicas y particulares y de la iglesia en todas sus manifestaciones. Se deben realizar cursos de conocimiento y concienciación en materia de los programas de reinserción social para que puedan impulsar con mayor fortaleza los mismos. Se deben crear departamentos de monitoreo y seguimiento de los egresados de los centros y reinsertarlos "en zonas agradables" para su mejor desempeño.

Además, los centros penitenciarios deben ser considerados según su capacidad, según el tipo de delincuente que se va a ingresar, si poseen enfermedades sistémicas (infecciosas), discapacidades y otras consideraciones. Las instalaciones deben estar en perfecto estado para poder cumplir con las necesidades primarias de los reclusos, no debe existir hacinamiento y los equipos destinados para realizar los programas deben estar en buen estado. Deben poseer el personal especializado idóneo y el adecuado personal de vigilancia, ya sean custodios o policías.

La sociedad en general debe estar en conocimiento de todos los esfuerzos realizados para evitar la reincidencia, apoyados por la información que en ese tema vierten los medios de comunicación. Debe estar preparada para poder absorber con propiedad a aquellos internos que se reinsertarán en sus zonas comunitarias para contribuir, a través de su labor, con el bienestar social. Las autoridades locales en cada caso deben apoyar esta iniciativa y coordinar acciones con los departamentos de seguimiento. Todo esto para disminuir la reincidencia delictiva y la criminalidad en nuestros países. Creo definitivamente que es una excelente opción. 


\section{REFERENCIAS}

- Bañón, Juan María. "Medios de comunicación, opinión pública y política criminal”, 27 de octubre de 2015. Acceso el 17 de febrero de 2017. http://decrimweebly.com

- Dirección General del Sistema Penitenciario. "DGSP y UP buscan introducir carreras universitarias en centros penitenciarios a nivel nacional”. Acceso el 26 de febrero de 2017. www.sistemapenitenciario.gob.pa

- Fuentes Osorio, Juan Luis. "Los medios de comunicación y el derecho penal". Revista Electrónica de Ciencia Penal y Criminología (2005): 3. https://dialnet.unirioja.es

- Maciel, Guillermo. "Un problema acuciante: la reincidencia delictiva". Acceso el 30 de septiembre 2005. eltelescopio.com.uy

- ONUDD (Oficina de las Naciones Unidas Contra la Droga y el Delito). Guía de Introducción a la prevención de la reincidencia y la reintegración social de los delincuentes. Nueva York: ONUDD, 2013, 1. Acceso el 24 de febrero de 2017. https://www.unodc.org

- Soto Navarro, Susana. "La influencia de los medios en la percepción social de la delincuencia". Revista Electrónica de Ciencia Penal y Criminología (2005). Criminet.ugr.es

- Pimentel, Kharla. "Del viejo al nuevo modelo penitenciario". Acceso el 28 de febrero de 2017. Acento.com.do

- Toledo Campos, Manuel. "Medios de comunicación y delincuencia: amplificación del miedo y creación de estereotipos". Dircom, Revista de la Universidad de Chile (2017): 1. www.uchile.cl 